\title{
EDITORIAL
}

\section{Rumo a uma práxis da engenharia em chave do Nepantla}

\author{
Gaitán-Albarracín, Nicolás*, Acero, Andrésº, Grisales Bohórquez, Claudiał̣, Serpa, \\ Bibiana $\nmid \dagger$, Reina-Rozo, Juan David 4 \\ * 17, Instituto de Estudios Críticos \\ ngaitana@unal.edu.co \\ - Escuela de Ciencias Exactas e Ingeniería, Universidad Sergio Arboleda \\ andres.acerol@usa.edu.co \\ $\uparrow$ Departamento de Informática, Universidade de Illinois \\ clg3@,illinois.edu \\ $\dagger_{\dagger}$ Escola Superior de Desenho Industrial, Universidade do Estado do Rio de Janeiro \\ bserpa@esdi.uerj.br \\ y Universidad Nacional de Colombia \\ jdreinar@unal.edu.co
}

Explorar o limite faz parte da nossa experiência como humanos, é desafiar o conhecido e encontrar-se com a alteridade, com o que existe para além da nossa própria existência, desse jeito é uma das empresas mais ambiciosas que a humanidade já criou. Nosso lugar, seja como pessoas, profissionais, membros de uma comunidade ou simplesmente como engenheiros, foi permeado por um milhão de interações históricas, ambientais e culturais. No entanto, a questão sobre as fronteiras é cada vez mais relevante. Assim, mais importante do que perguntar-se pela inegável possibilidade de viver em espaços liminares, onde fazemos parte de algo mas também do outro, com limites cada vez mais difusos, é a constante reflexão sobre o que significa Nepantla ${ }^{1}: 0$ espaço entre o aqui e o lá. É por isso que esse número presta homenagem a esse processo,

\footnotetext{
${ }^{1}$ Nepantla representa um conceito de "intermediário". É um espaço liminar, onde múltiplas formas de realidade são vistas ao mesmo tempo. Para Anzaldúa, nepantla tem vários significados que se sobrepõem e se enriquecem. Representa espaços liminares, períodos de transição na formação da identidade, o "estágio do nascimento em que você sente que está reconfigurando sua identidade e não sabe onde está". Um espaço que facilita a transformação; à medida que os limites são rompidos, as categorias de identidade que antes eram tão confortáveis, tão naturais, já que não funcionavam mais; eles se dissolvem, forçando-nos a encontrar novas maneiras de nos definir. Nepantla também funciona como uma metáfora do conhecimento proibido, novas perspectivas sobre a realidade, formas alternativas de pensar. O "estado liminar entre mundos, entre realidades, entre sistemas de conhecimento". Anzaldúa, G. (2000). Entrevistas: Entrevistas. Routledge p. 4.
} 
desafiando os limites da engenharia, da tecnologia, da linguagem, do estilo, da forma, do espaço, da construção e desconstrução sobre a própria fronteira.

Dessa forma, esse número foi criado a partir de uma chamada trilíngue, ou seja, do convite a pessoas e grupos dos quais sua língua seja espanhol, português e / ou inglês. Assim, nos nutrimos de suas particularidades epistemológicas e ontológicas, expressas por suas palavras. É um convite a ser múltiplo desde nosso ser, fazer e sentir a prática da engenharia, a criação e o uso da tecnologia, cruzada com a missão da justiça social e a construção da paz neste mundo cada vez mais convulsivo. Portanto, esta é uma oportunidade de nos tecermos como um continente mas de outras maneiras, dando um passo para romper as fronteiras, por enquanto, da linguagem e das disciplinas, para continuar com a geopolítica. Este grupo excepcional do comitê editorial deseja que, com esses textos, possamos viver no Nepantla, o liminar, nem aqui nem lá. Apenas sendo... e devir, transformando-se continuamente: nos projetando através das fendas da virtualidade ${ }^{2}$.

Nesta edição, com o desejo de ser outres, além de nos aventurarmos pela primeira vez em outra lingua, também quisemos experimentar outros formatos. Refletindo sobre que tipo de publicações teríamos que conhecer dos nossos seres e nossos sules, e achamos que há várias pessoas que cruzaram nossas vidas e que percorreram longos caminhos para transformar a engenharia. No entanto, essas pessoas são conhecidas apenas por quem interagiu com elas em projetos, cursos, eventos e outros experimentos criativos nos quais nos aventuramos. Assim, como engenheires múltiples, experimentamos no jornalismo para documentar, comunicar e explorar as vidas e reflexões das pessoas que nos cruzaram nesse caminho. Humanos que reconhecemos como seres únicos e que realizam essas buscas transformadoras por toda a vida. Para este volume, convidamos um engenheiro colombiano: Ernesto LLeras Manrique.

A caminhada pelo liminar nos permitiu experimentar mundos não convencionais e não hegemônicos, dialogar entre a engenharia, a paz e a justiça social. Não aceitar a pressa modernizante dessas disciplinas que raramente questionam o desenvolvimento. Agora, como engenheires cada vez mais envolvidos na construção de mundos materiais é necessário estar ainda mais conscientes que essas disciplinas estão cheias de ideias e valores de como devem ser as relações sociais "adequadas". O coração das nossas disciplinas é inerentemente político. Ao reconhecer esse elemento característico da nossa profissão, os olhos com os quais percebemos nossas realizações do mundo mudam, e as mãos com as quais construímos essa materialidade são convidadas a ser mais cuidadosas, mais democráticas, mais sutis e mais diversas. Depois de desconstruido o mito da neutralidade na nossa prática, as responsabilidades do nosso quefazer diário são menos obscuras para nós mesmos e, por isso, temos perguntas como a seguinte:

${ }^{2}$ Deleuze, G., Guattari, P. F., \& Pérez, J. V. (2004). Mil mesetas. Pre-textos. IJESJP, 2020, V7, n2 
continuaremos replicando o mundo dos outros ou vamos construir mundos coerentes com nossas apostas vitais?

Com essa grande responsabilidade, não podemos cair em pesadelos tecnófobos, ou em utopias tecnófilas, agora nosso chamado é ser cada vez mais, mas e mais o que? mais humanos, mais do que humanos, mais engenheires, mais integrais... Quando nossa prática profissional se torna cada vez mais integrada com nossos outros eus, podemos começar a construir outros mundos com bases sólidas, fundações que não serão apenas o suporte estrutural, mas isso se tornará na própria superfície do nosso habitar. Quando o fundo e a superfície das nossas práticas são diluídos, a nossa experiência de habitar será o Nepantla. Vamos nos inspirar todos juntos nas contribuições dos nossos autores para rastrear as dicas sobre como percorrer esses outros habitats.

Inicialmente, o artigo apresentado por Jorge Rojas e Adrián Wong, chamado Investigação Cidadã e Prevenção ao Crime na cidade de Urbana, Illinois - Estados Unidos, explora a relação entre a visualização de dados abertos do governo local de Urbana e os desequilíbrios relacionados à redes de comunicação, capital cultural e medição do crime. O objetivo principal é gerar modelos alternativos para entender e medir as relações entre a polícia local e a comunidade do distrito 3 . A partir da Pesquisa-Ação e do conceito de Nepantla, os autores derivam sua análise da pesquisa ou ciência cidadã. Portanto, eles possibilitam uma relação sem precedentes entre dados abertos, no nível do uso da tecnologia pública e na dinâmica da polícia e da comunidade.

Por outro lado, o artigo de Sara Idárraga, Alexei Ochoa e Leonardo León, intitulado Sementeira de pesquisa-ação PARES, um processo de práxis nos territórios, apresenta a experiência de trabalhar com comunidades rurais de um coletivo interdisciplinar de uma universidade colombiana. A partir do referencial teórico-político da Pesquisa Ação Participativa e da Pedagogia da Libertação, eles estabelecem as bases para o desenvolvimento de atividades de apropriação social da tecnologia em dois territórios que, após o Acordo de Paz com a guerrilha das FARC, têm novas dinâmicas sociais, políticas e tecnocientíficas. Esses terriotorios são o Espaço Territorial de Treinamento e Reincorporação Antonio Nariño, em Icononzo - Tolima, e o povoado de Puerto Matilde, no município de Yondó - Antioquia. No final, eles apresentam uma série de desafios do grupo diante de suas iniciativas e ações futuras.

Enquanto isso, o artigo escrito por Antonio Lafuente, intitulado Ciência aberta para mudar o mundo, oferece uma visão crítica do paradigma emergente da Ciência Aberta. Refletindo sobre as implicações dessa noção não apenas na academia, mas também na cidadania, o autor tende a expandir o diálogo dos saberes para outras dimensões da construção do conhecimento. Antonio exprime que a Ciência Aberta cria as condições para fazer mais porosas as fronteiras entre academia e sociedade, e explora a relação entre as formas de acesso aberto e os atores emergentes envolvidos neste processo contínuo de abrir as ciências, ou melhor, de abrir a vida acadêmica.

IJESJP, 2020, V7, n2 
Por fim, ele defende as implicações da abertura da ciência, incluindo a governança dos processos de geração de conhecimento e a soberania das comunidades científica e cidadã.

O artigo Sistema Integrado de Comercialização para Produtos da Agricultura Familiar de Celso Alexandre Souza de Alvear, Larissa Bral Povoa de Hora, Fernando Dias de Mello Silva, Pedro Jullian Medina Torres Graça, Rosimar Caroline Batista Ferreira e Gabriel de Avellar Amorim descreve a experiência do Núcleo de Solidariedade Técnica (Soltec/NIDES/UFRJ) no desenvolvimento de um sistema de informação e gestão para a comercialização de cestas agroecológicas no estado do Rio de Janeiro. O trabalho mostra a formação de uma racionalidade técnica diferente da tradicional, intencionalmente política, dialogando com o desenho participativo, a política rural brasileira e os princípios éticos das organizações de base que promovem a agricultura familiar e a agroecologia no Brasil. As decisões que a equipe de trabalho toma no design e na implementação do sistema refletem esses diálogos, enquanto uma avaliação da tecnologia revela seus impactos e oportunidades de melhoria, reconhecendo-a como um elemento localizado em uma rede sociotécnica, sempre provisória e em constante criação.

$\mathrm{O}$ artigo de Cristiano Cordeiro Cruz, intitulado Práticas nepantleras da engenharia e os desafios de se formarem engenheiros/as capazes de aplicá-las e aprimorá-las é um convite para repensar processos educacionais transformadores, delineando os caminhos pedagógicos para o ensino de engenharia desde a compreensão do conceito Neplanta, de Gloria E. Anzaldúa. O autor questiona a ordem sociotécnica hegemônica e nos faz refletir sobre abordagens de engenharia que propõem práticas participativas e dialógicas capazes de ocupar o lugar "Neplanta". Com base nessa reflexão, são propostas atividades pedagógicas que poderiam treinar engenheiros/as neplanteros/as e educadores.

Por fim, encerramos o volume abrindo nossa seção de entrevistas com Uma vida de resistência passiva desde a engenharia. Entrevista com Ernesto Lleras Manrique. Nesse diálogo, entramos na vida de Ernesto, perifericamente, cercando suas propostas fundamentais de trabalho: TESO e Comunidades de Aprendizagem. Nesta viagem, exploramos algumas de suas experiências vitais em relação à engenharia e educação, depois passamos por suas críticas à profissão na Colômbia, suas influências intelectuais e alguns momentos vitais que deixaram sua marca nele, para sempre observar atentamente e refletir sobre o significado do nosso quefazer.

\section{Convite editorial}

Somos cinco e cinco somos, embora, para esta tarefa, procuremos ser um. Um com um objetivo comum, como a idéia de Convite, uma relação de trabalho camponesa guiada pelo interesse coletivo, um reencontro solidário, outro compartilhamento mais!

IJESJP, 2020, V7, n2 
Então, sem esquecer a unidade, nos quebramos momentaneamente para apresentar o que, neste caso, nos trouxe para a unidade. Esperamos, com tempo e amizade, os colaboradores deste Convite serão mais.

\section{Andres Acero}

Encontrar e criar espaços para desafiar os limites do que acreditamos, do que fazemos e até onde podemos ir são a minha obsessão. Portanto, trabalho para construir a sociedade a partir dessa fronteira invisível que falsamente inventamos, a fronteira do engenheiro e da comunidade. Uma nova visão é construída quando aprendemos a nos ver, a nos pensar e é isso que quero que todos a quem eu chegue possam conseguir. Você tem se pensado também?

\section{Bibiana Serpa}

A construção de uma sociedade mais justa e igualitária começa por imaginar outro mundo possível. A utopia desta crença me mantém com esperanças e creio na transformação a partir da práxis feminista anticapitalista. Sou designer e trabalho com educação popular buscando me engajar em práticas políticas e criativas que permitam a emancipação individual e a mobilização coletiva para a transformação da realidade.

\section{Juan David Reina Rozo}

Andou várias geografias, a fim de conhecer práticas de base da ciência e da tecnologia contextualizada, criando uma prática alternativa da engenharia junto às comunidades no nível local, desde a exploração, a experimentação e a prototipagem em comum. Também está interessado na relação entre a construção da paz, a tecnociência e a inovação em ambientes locais.

\section{Nicolas Gaitan-Albarracin}

Todos os dias devenho outro, e hoje em dia devenho semente, estou me permitindo sonhar. Sonho com outra materialidade possível, ou melhor, dou às apostas dos nossos sonhos um maior grau de realidade. Nesta ocasião, estou explorando a entrevista para a revista como outra maneira de documentar a vida de engenheires que marcaram nossos 
caminhos. Gosto de fluir com a natureza e hoje conheço pessoas que estão construindo outros mundos possíveis para apoiar sua articulação.

\section{Claudia Grisales}

Movimenta-se nas interseções entre ciência, design, estudos sociais da ciência e da tecnologia e o trabalho comunitário, procurando maneiras de envolvê-los no cuidado contínuo da terra e na construção de alternativas ao desenvolvimento.

\section{Chamada de artigos - Removendo limites entre disciplinas}

Esta chamada busca contribuições que analisem criticamente e teorizem sobre a intersecção entre justiça social, feminismo, filosofia e epistemologia com a disciplina de engenharia. Convidamos os autores a explorar o que Gloria Anzaldúa definiu como Nepantla - o espaço limiar, o intermediário e os limites desde os quais emergem novas idéias. A engenharia cobre uma ampla gama de conhecimentos e de fronteiras metodológicas. Uma conseqüência dessa amplitude é o potencial enfraquecido de múltiplas formas de avaliação e reflexão que restringem as possibilidades de perspectivas críticas únicas. Esta é a "Nepantla" que procuramos explorar. Esta revista está aberta a conhecimentos transdisciplinares que removem as fronteiras da engenharia para enriquecer o discurso acadêmico de nossa profissão. Contribuições de todas as áreas acadêmicas são bem-vindas, incluindo artigos de estudantes de graduação, poesia, prosa e obras artísticas.

A Revista Internacional de Engenharia, Justiça Social e Paz é dedicada à teoria e prática da engenharia que visa a justiça social e a paz em todo o mundo. Nossa abordagem trabalha em prol de práticas de engenharia que abranjam equidade de gênero, raça, classe e cultura e que sejam democráticas, não opressivas e não violentas. A revista serve engenheiros, educadores na área e o público em geral que procura entender o potencial progressista da engenharia. Os artigos desta revista são revisados por especialistas, um processo que acomoda pesquisadores e professores e outras partes interessadas.

As submissões para esta edição até 15 de outubro de 2019. 
Gaitán-Albarracín, Acero, Grisales Bohórquez, Serpa, Reina-Rozo

Rumo a uma práxis da engenharia em chave do Nepantla

IJESJP

\title{
Revisores que participaron en este número
}

\author{
Antonela Isoglio \\ Cristiano Cordeiro Cruz \\ Diego Fernando Martinez Castro \\ Farid Eid \\ Fernanda Araujo \\ Laís Fraga \\ Luis Fernando Medina \\ Luisa Fernanda Payan \\ María Catalina Ramírez \\ Mariano Fressoli
}

